\title{
Don Antonio Gómez Restrepo y su Obra Literaria
}

\author{
La crítica
}

$\mathbf{L}^{\circ}$ OS juicios literarios, por lo mismo que se refieren à obras humanas, en lo general caducas o tocadas de imperfección, de cuyo mérito deciden las modas reinantes y en última instancia como supremo juez el tiempo, no pueden tener el alcance definitivo que nace de afirmaciones o de negaciones absolutas. De ahí que ni los más expertos críticos, ni mucho menos los mismos creadores de belleza, estén suficientemente capacitadós para decir a un libro, a un drama o a un poema: vive tu inmortalidad, eres eterno.

Casos como el de Larra, cuando escribió aquel juicio profundo e inapelable que no han desmentido los años, sobre Los amantes de Teruel de Hartzenbusch, no se dan todos los días; en cambio, sabemos del mismo Cervantes la preferencia que él daba en mérito al Persiles sobre el Quijote; y es muy frecuente ver aplaudido y estar en boga un libro que a pocos soles rueda en el polvo, o rebajado otro que pronto cobra nombre imperecedero. QQuién hubiera anunciado a fines del siglo XV -en que vieron la luz - la inmortalidad a que estaban destinadas la Celestina de Rojas y la Elegía de Jorge Manrique, esos dos grandes monumentos de la lengua! :Qué raros los que en estas materias pueden decir la última palabra!

A veces entra por mucho la sugestión, no ya de un individuo sino de una época, como sucedió con el falso Ossián; en otras deciden una errada tradición, la rutina, la superficialidad, como aconteció con el Centón epistolario atribuído a Fernán Gómez de Cibdadreal 
(que se ha sabido ser superchería literaria debida, según se cree, a Gil González de Avila), y que en los tratados de historia de literatura española se venía dando por monumento de prosa antigua y dechado de pureza del tiempo de don Juan II y don Alvaro de Luna, hasta que empezó a dudarse de su autenticidad, la cual llegó a desbaratar enteramente, por el punto del lenguaje, a que nadie se había atrevido, mediante la más científica y sutil crítica filológica, el maestro de los maestros y el más sabio de sus cultivadores españoles: Cuervo.

Así pues, no será mucho que tratándose de autores próceres contemporáneos, críticos de una misma época difieran radicalmente en sus apreciaciones. Menéndez Pelayo, el incomparable poligrafo, pasmo de una edad que ha dado tantos grandes hombres, ensalzado de alta manera por Boris de Tannenberg, Valera, el padre Del Valle Ruiz, Rubén Darío, Gómez Restrepo y tantos más de todos los países, en todas las lenguas, ha sido negado en su aspecto de crítico, entre otros, para sólo citar autores de nota, por el escritor paraguayo Manuel Domínguez, a quien combate victoriosamente Francisco García Calderón.

El gran crítico español Francisco Navarro Ledesma dice de Bécquer que "logró inmensa popularidad, superior en general a sus méritos", pretendiendo destruir de una plumada los altares que la conciencia literaria española y universal levantó al bardo extraordinario que formó escuela y comprobó la superioridad de su ,estro con haber tenido, como tuvo, una legión de imitadores.

Entre nosotros, se ha desconocido a Caro su enorme valía como crítico, bien que sin fundamento apreciable, pues no se aducen razones de peso que mantengan de pie tan audaz afirmación; en tanto que el ilustre Merchán, Menéndez Pelayo, Gómez Restrepo y otros como Rufino Blanco-Fombona (quien llama a Caro, con manifiesta exageración, "el enorme crítico clásico, superior a todos los Menéndez Pelayo y a todos los Valeras de España, y sólo comparable a Andrés Bello"), han probado que las armas del excelso traductor y comentador de Virgilio - del que escribió juicios como los relativos a Julio Arboleda, a Olmedo, a Cervantes, a José Eusebio Caro, a Bello, a Menéndez Pelayo, a Núñez de Arce, a Fallon y en general a muchos otros poetas y escritores españoles, nacionales y extranjeros-, pueden lucir muy cerca o a la par de las de Taine o Sainte-Beuve. 
¿Qué mucho, si figuras de la talla de Forbes, Johnson, Green, Rhymer, Shaftesbury, Dryden, Foote, Pope, Voltaire, Tolstoy y cien más han tratado de oscurecer o amenguar la fama de Shakespeare, de quien dicen sus compatriotas que en cambio de perder sus obras darían sus posesiones de la India y mucho más! Y el mismo Platón, con Pitágoras, Erasmo y tantos más -forman legión- ¿no han combatido rudamente y aun negado a Homero?

Por otra parte, hay que tener en cuenta la diversidad de opiniones y procedimientos adoptados por los críticos en el espacio y en el tiempo. Para no ir más lejos, en el siglo XVIII y principios del XIX el método consistía en examinar las obras a gusto del que escribía, y aun de un grupo, o de ciertas tradiciones. Viene SainteBeuve, y según su método hay que enterarse de la patria inmediata del autor, de su raza, etc., para deducir sus facultades de las de sus ascendientes; investigar sobre su niñez, educación, etc., y para justipreciarlo bien, compararlo con sus antagonistas y con sus discípulos; y muchas otras circunstancias. Según Taine, hay que remontarse de la obra literaria al hombre fisiológico que la ha producido; de éste, al hombre interior, a su alma; luego, a las causas mismas de esta constitución psicológica que viene a resumirse en la raza, en el medio físico y social, en el momento; es decir, que ello vale tanto como escribir la historia de una literatura para rastrear por ella la psicología de un pueblo. $Y$ siguen otros y otros, en cadena interminable, cada cual con su fórmula, con su clave y con su método, así como van pasando los autores, cada uno con su estilo y todos juntos con su fracaso o con su gloria.

De todo punto impónese la crítica, y más a medida que se va desarrollando la cultura. A veces resume el arte nacional; a veces, como hizo Lessing en Alemania, lo suscita. En todo caso, es guia y consejera, alienta, estimula, o discerniendo el trigo de la paja, cumple obra patriótica perdurable, como lo hace el maestro que ilumina las generaciones.

¿Y qué es la crítica? ¿Y cómo ha de ser la crítica?

Queremos hacer notar cuán digno de consideración es atemperar el criterio a ciertas normas en este género tan escasamente cultivado entre nosotros, si bien algunos maestros, de que luego hablaremos, le han dedicado no pocas vigilias, no obstante lo que podríamos llamar abundante producción literaria en esta tierra de 
escritores, periodistas y poetas. De ese modo puede acaso suceder que su ejercicio - si hay quien se atreva a acometerlo- se acerque, por lo menos, a la perfección; y que eso, a par de la sinceridad, sea la defensa ante la voz de lo futuro, si éste no aprueba los fallos, o la satisfacción del acierto, si ha de confirmarlos.

Ni la férula de "Clarín", ni la excesiva benevolencia de Valera, ni la depresiva jocosidad de Valbuena cumplen el ideal del crítico moderno. Veamos por qué no.

"La crítica -dice Amiel, Diario intimo- es un dón especial, es tacto, olfato, intuición; no se enseña ni se demuestra: es un arte. El genio crítico es la aptitud para discernir la verdad bajo las apariencias y el embrollo que la ocultan; es descubrirla a pesar de los errores del testimonio, de los fraudes, de la tradición, del polvo de los tiempos, de la pérdida o de la alteración de los textos; es la sagacidad del cazador a quien nada engaña durante mucho tiempo y a la que no despista ninguna estratagema; es el talento del juez de instrucción que sabe interrogar a las circunstancias, y de mil mentiras hace brotar un secreto insospechado. El verdadero crítico sabe comprenderlo todo, pero no consiente ser engañado por nada, sin sacrificar a ninguna convención su deber, que consiste en hallar y decir la verdad. La erudición suficiente, la cultura general, la probidad absoluta, el buen golpe de vista, la simpatía humana, la capacidad técnica, eso y más es indispensable al buen crítico, sin contar con la gracia, la delicadeza, el conocimiento del mundo"...

Caro, el maestro, da el ejemplo y la regla: "La crítica verdadera es luz y no eclipse. Ella es incorpórea: ilumina los objetos para aguzar la visión del espectador, no para entorpecerla; $y$ hace los objetos visibles y hermosos sin alterarlos. El crítico y el historiador han de mostrarse por los efectos mágicos que producen, no por la vana ostentación de su impertinente personalidad; por eso el crítico, como el historiador, sin dejar de ser exacto y científico, ha de tener no poco de poeta o artista, así como la luz embellece las cosas sin perjuicio de una absoluta fidelidad".

Otro maestro moderno -Rodó- refiriéndose a Francisco Garcia Calderón, enseña de este modo: "La crítica es el más vasto y complejo de los géneros literarios; rico museo de la inteligencia y la sensibilidad, donde, a favor de la amplitud ilimitada de que no disponen los géneros sujetos a una arquitectura retórica, se confun- 
den el arte del historiador, la observación del psicólogo, la doctrina del sabio, la imaginación del novelista, el subjetivismo del poeta. Cultive el joven escritor tan vasto campo, y cultívelo de manera que en él se hermanen la fecundidad y la gracia, enseñoreándose cada día más de los instrumentos que para ello son precisos: el criterio, reacio a todo yugo, lo mismo tradicional que nuevo; la tolerancia, no sólo la que es luz intelectual, sino también calor de sentimiento, penetrante fuerza de amor; el interés fácil y vario, siempre pronto a acudir a donde quiera que un alma piense, sienta $\mathfrak{u}$ obre; la virtud de la expresión, inseparable de los matices del pensamiento, y por lo tanto auxiliar eficaz de la investigación y del análisis".

"Este ministerio u oficio literario y científico es uno de los más difíciles que pueden realizarse - dice Navarro Ledesma, quien no sólo da el precepto sino el ejemplo-. Para ser buen crítico hace falta poseer todas las facultades y cualidades del escritor con la mayor extensión e intensidad. No quiere esto decir que sea cierta la opinión del vulgo, según el cual, para juzgar si es buena o mala una obra, se necesita saber hacer otra igual o mejor. Lo que se necesita es comprenderla bien, sentirla; dejándose impresionar profundamente por ella, $y$ amando lo que haya en ella de bueno; observarla con mucha atención y reflexionar detenidamente acerca de ella, llegando a descubrir en su fondo y en su forma lo que se ha escapado a la consideración irreflexiva del público lego o falto de cultura; tener habilidad, ingenio y a veces verdadero genio para adivinar y descubrir racionalmente y sin ficciones imaginativas los ocultos propósitos y tendencias del autor; poseer sólida y completa erudición en todas las ciencias y disciplinas relacionadas con el objeto de la obra y con su fin; conocer o presentir los efectos que en la humanidad deben causar la obrá y las ideas y sentimientos en ella expuestos, y finalmente tener gusto acendrado, originalidad verdadera y estilo propio, para que la crítica resulte digna de la obra a que se refiere".

Pudiera parecer inoportuno este largo preámbulo, pero no lo es, si se considera que no está mal desengañar a tantos escritores acerca de lo que ellos creen ser la crítica y el arte de escribir, comparado con la inmensa realidad de lo que son tan altas disciplinas. Otro motivo de este acopio de doctrinas y juicios acerca de la crítica, 
está en la necesidad de poner sólidas bases a las observaciones que han de venir sobre la magna obra de nuestros grandes críticos, especialmente la de don Antonio Gómez Restrepo, que estudiamos.

En Colombia, Caro, el humanista incomparable, forma con Baldomero Sanín Cano y con Antonio Gómez Restrepo la más destacada agrupación de críticos cuya obra perdurará, por lo sólida y luminosa, a través de las vicisitudes literarias; cada uno cumple a maravilla su tarea, y los tres hacen un todo armónico que honra por extremo las patrias letras. Caro es el dialéctico, que basa sus juicios en la lógica y con frase metálica analiza a un autor, deduce un parentesco literario, define eruditamente una situación y fija definitivamente el valor de una obra; Sanín Cano, en frase escueta y con acopio de datos propios y ajenos, con tendencias más a lo moderno que a lo antiguo, nos da el análisis científico de un libro y lo que vale el empeño literario de su autor; Gómez Restrepo aprovecha su vasta erudición literaria española y universal, sus altas dotes de poeta, su cultura clásica y su acendrado gusto, para decirnos, en cuadros sintéticos acabados, lo que es y lo que vale un autor colombiano o americano, un ciclo de literatura española, un autor italiano, o francés, o inglés, o alemán, o ruso, o polaco, o toda una época de literatura universal. Sería de desear que alguna experta pluma estudiara a estos tres maestros de la crítica colombiana y que, en sintesis sabias, nos hablara de sus labores y de su influencia en nuestra literatura, pues ya es llegada la hora de que nos preocupemos más por lo de casa, si no queremos vivir siempre bajo la dependencia de yugos literarios extranjeros y postizos.

De Baldomero Sanín Cano, el maestro de dos generaciones colombianas, no puede hablarse sino con el respeto y la estimación que merecen los grandes varones que en nuestra patria han consagrado toda una vida al servicio de las letras, pero no así como se quiera, sino con el talento y la eficacia necesarios a producir en el concepto de propios y de extraños el juicio consagrador y definitivo que da el pasaporte para la celebridad. Experto en literaturas y lenguas extranjeras; maestro en lo que se refiere a lengua y letras españolas, lo que es decir filólogo y letrado; conocedor de los distintos sistemas filosóficos y dueño de los demás recursos que ha menester la crítica para su mejor desempeño, a lo que se agrega el caudal de cultura que del constante viajar por los grandes centros 
civilizados reportan los hombres ilustres como él; por todo eso no será extraño que las personas capaces de apreciar y comprender la obra del espíritu, el poder de las nobles y puras y bienaventuradas ideas -que Platón decía- consideren el apostolado literario del maestro Sanín Cano como una de las pocas empresas espirituales que honran a la patria.

\section{Gómez Restrepo, crítico}

Gómez Restrepo llegó al palenque literario armado de todas armas, y desde luego se presentó como maestro, ya en orden a la crítica, ya considerado como poeta y escritor. Su primera poesía, hecha a la edad de doce años, "I a profecía del canónigo", lo confirma. Célebres fueron sus polémicas sobre el hiato y otros puntos con el eminente crítico cubano Merchán, allá por 1884; y hay quienes no olvidan la profunda impresión que produjeron algunos estudios del entonces joven literato, publicados en el Repertorio Colombiano, como el que con título "Sobre poemas" vió la luz pública en el año de 1897.

Viajó por Europa y desempeñó la secretaría de la legación de Colombia en Madrid, donde, en contacto con los maestros de la Península, le bebió mejor los alientos a la literatura española; conoció y trató a los ingenios de ese tiempo: Núñez de Arce, Campoamor, Valera, la Pardo Bazán; y oyó de la misma boca de Menéndez Pelayo las sapientísimas lecciones con que el incomparable polígrafo enseñaba y deleitaba al mundo entero. En Roma acendró su sabiduría clásica sobre el mismo suelo que sustenta los monumentos y emblemas de la ciudad eterna, los cuales cantó de alta manera en sonetos de acabada forma, que son otros tantos monumentos de la lírica; y allí mismo publicó años después, para deleite de los amantes de la belleza, la traducción de los mejores cantos de Leopardi, que antes había escrito en Bogotá, con tal perfección de forma y tal devoción por el autor, que se duda haya entre los intérpretes del bardo italiano alguno que pueda igualarse siquiera al traductor colombiano.

Restituído a la patria, después de haber hecho famoso su nombre por tierras de España y de América, el gallardo escritor volvió a sus libros y a su pluma (que no ha soltado desde entonces, por lo 
cual entra Gómez Restrepo en la agrupación de los verdaderos literatos, según el concepto de Fichte), y con tal fecundidad ha dado desde entonces producciones tan buenas y admirables, concernientes al arte y a la crítica, que, a publicar sus dispersos artículos y discursos, ocuparían una serie de volúmenes que en verdad podrían ponerse al lado de las obras de Caro y de Suárez, ya que todos tres han sido, con Sanín Cano y pocos más, los más preclaros y constantes forjadores de la prosa en Colombia.

El Nuevo Tiempo Literario, Revista Moderna, Trofeos, Cromos y en general toda publicación literaria de la capital y de otros lugares, han honrado sus páginas con estudios críticos de Gómez Restrepo, que son leídos por el público inteligente con extrema simpatía, en términos que si faltara en esas revistas y publicaciones la firma del egregio escritor hallaría descabaladas sus lecturas, y con razón, porque faltando las lecciones del maestro, como que sobran las sabidurías de los discípulos, pues hay maestros irreemplazables.

Quien quiera saber quién es Gómez Restrepo en punto de crítica literaria, analice cualquiera de sus estudios, haga a un lado las teorías más o menos científicas de los reputados como supremos maestros de la crítica, aténgase a lo que dejamos transcrito del filósofo ginebrino, de Caro, de Rodó y de Navarro Ledesma, y vea si nuestro crítico no satisface completamente esos ideales.

Ora estudie a los autores españoles: a Menéndez Pelayo, a Ricardo León; o a los franceses e italianos: un Barrès, un Rostand, un Carducci; o a los ingenios americanos: un Caro, un Cuervo, un Pombo, un Isaacs, un Fallon, un Rodó, un Dario... deja siempre al lector satisfecho, porque cada juicio de esos es una obra maestra que allá se las ha con las mejores de Revilla, "Clarín" o Ganivet. Acaso sus más notables trabajos críticos sean los que dedicó a Menéndez Pelayo y a Cuervo (donde está uno de los más bellos elogios que se han hecho de nuestra lengua), y en los cuales derrochó elocuencia, sabiduría, entusiasmo, con admiración de propios $y$ de extraños. $Y$ como un modelo de sintesis pueden considerarse el compendio de literatura colombiana publicado en la Revue Hispanique, y la introducción que escribió para el parnaso colombiano de Ory, en las cuales, con pocas pinceladas maestras, nos da el retrato de nuestros poetas y literatos, cuyo conjunto así considerado cons- 
tituye el cuadro más perfecto que se ha escrito sobre la literatura colombiana. Leamos un fragmento:

"La influencia de Bécquer sobre José Asunción Silva (18651896) es visible en los versos que publicó La Lira Nueva. Hay exquisita delicadeza y la preocupación altamente poética del más allá en 'La crisálida', símbolo de la inspiración del vate en sus luminosos comienzos. Un temprano viaje a París lo puso en comunicación directa con la literatura francesa, y fué desde entonces el más parisiense de nuestros escritores, sin perder por eso el carácter bogotano heredado de su padre don Ricardo. Porque Silva así volvía los ojos con hechizo hacia las viejas tradiciones y los cuentos infantiles, como miraba ansioso a lo porvenir, queriendo anticiparse a las futuras revelaciones de la ciencia y el arte. En otro trabajo nuestro citamos una página del insigne escritor francés Andrés Suarès sobre Baudelaire que puede aplicarse punto por punto para caracterizar la vida y el genio de Silva. Pero la poesia de éste, si entraña una renovación por el aspecto de la sensibilidad y produce un frisson nouveau, como toda manifestación sincera de arte superior, no rompe la cadena de la evolución poética en Colombia. Silva tiene su puesto en seguida de Diego Fallon; a quien admiraba mucho y a quien dedicó una linda poesía. Los versos de Silva son de irreprochable perfección artística, y amplianse pero no rompen los moldes de la versificación tradicional. Jamás hizo versos cojos con el pretexto de enriquecer la métrica castellana, debilidad en que incurrió el propio Rubén Darío. Silva es original y grande por el sentimiento hondo, amarguísimo, de quien ha probado en la primera juventud todos los jugos de la vida $y$ en todos ha hallado gérmenes letales; por la distinción y elegancia con que traza cuadros que recuerdan las telas de Watteau y de Boucher; por la intensidad del pensamiento, que gespierta en el alma hondas vibraciones; por esa mezcla de ingenuidad y de pesimismo, de idealidad y de ironía que hace de sus cantos tin fruto de sabor nuevo en nuestra literatura. No se ha estudiado todavía la psicología de Silva ni el proceso intelectual y sensitivo que lo condujo de las auroras de 'En marcha' a la negra noche de 'Las gotas amargas', que ya no recuerdan a Bécquer sino a Bartrina, y a la noche más sombría del suicidio: Silva puso fin a su carrera antes de cumplir los treinta años. Si hubiera vivido más, es probable que hubiera disputado a Dario el cetro de la poesía 
modernista, no sólo en América sino en España. El 'Nocturno', su más popular composición, es una de las piezas capitales del arte nuevo; es una de esas raras y felices inspiraciones en que un sentimiento profundo y casi inefable halla un motivo poético que lo exprese y una forma plástica que lo encarne; vaga sinfonía que suena como cosa inaudita, y que sin embargo está constituída con elementos de admirable sencillez. Pocas veces la música ha brotado tan íntimamente de las entrañas del tema y ha alcanzado un poder evocador tan grande".

¿No es la anterior una página de arte que aplaudirían sin restricciones los grandes maestros de la crítica?

Así pues, no será extraño que eminencias como Cejador le dediquen alguna de sus obras al crítico bogotano, en són de estima y de admiración, y que altas personalidades de las letras extranjeras reclamen su amistad y honren su nombre con altísimos conceptos; el padre jesuita Zorrilla de San Martín lo cita elogiosamente en su tratado de literatura universal.

En Colombia todo escritor de las nuevas generaciones (excluyendo por supuesto a los novísimos), todo el que escriba y piense, tiene a señalada honra llamarse discípulo de Antonio Gómez Restrepo: él es el maestro. Si el criticar es arte complicado, en que intervienen cualidades de filósofo, de historiador y de artista, como quiere Sainte-Beuve, él es nuestro crítico; y si el escribir es cosa de ciencia, conciencia y paciencia, como dijo Caro; si es imponerse a las gentes por la alteza del pensamiento, por la sinceridad y el calor del corazón, él es nuestro escritor.

\section{El poeta}

i Tiempos menguados para las letras patrias los últimos tiempos! Antes un poeta, un escritor, eran rara avis, y como representaban la flor de una raza, la selección intelectual, merecían y recibían aplausos y parias; distinción y dilección que naturalmente se justifican y evidencian, porque, según dice un autor francés, "si la ciencia es grande porque separa de la mediocridad, el ideal también necesita un seguro y una casta, lo cual explica la dignidad de toda aristocracia exclusiva". Por eso, para alcanzar el aere ferennius, además del andra agathon que pedía el griego, exigía Horacio en el poeta 
mens divinior, esto es, más que divina. Raza de semidioses, los poetas.

A poder simbolizar la patria en algo corpóreo, fingiríamosla a guisa de inmensa pirámide que, arrancando de lo hondo del suelo, tocara con su vértice en las nubes. Cada cara, un ideal: religión, lengua, historia, letras, leyes; en el ápice, la justicia; y más arriba, una llama oscilante, que por sutil milagro fuese música y a la vez perfume y canción: la poesía. Aérea, alta, sublime, diríamos que es el alma del alma de la patria. Para aspirar a esa cumbre son menester alas movidas por espíritus divinos. (Ovidio decía que los poetas están asistidos por un dios). Lo demás, profanación. Tiemblo por ti, como el ojo de la paloma, que Sófocles decía, cuando mido tu espíritu en tus versos, sin música, sin hálito, sin alas; si no los sabes vaciar en ardiente crisol para soltarlos como saetas áureas que han de volar de siglo en siglo; si no ha de vivir de ellos siquiera un hemistiquio, que será mucho quedar, ¿a qué ese afán de metros que te enajena los sentidos? ¡ Poeta! ¿Quién dijo esa palabra? Cuando leo a Homero -exclamó alguno- me siento crecer como un dios: ¿qué diremos de los novísimos discípulos de Apolo?

Hoy el arte, si no se ha aplebeyado, se está puerilizando; es un árbol tan accesible, del baobab que era, que no hay mano que deje de alzarse, en arranque destructor, al tronco vacilante. Hoy, como en los buenos tiempos de Juan Alfonso de Baena, pueden alternar con el sastre Antón de Montoro, en los solaces poéticos, los próceres de Villena o de Santillana, o el ardido lidiador Stúñiga, sin desdoro ni rebajamiento propio. Espadas y asadores todo es uno, por lo que al arte toca, en estos tiempos igualitarios y felices. "Mi pluma", dice como Montalvo el primer azacán; "mi lira", exclama el último pichón literario de aldea, "el más barbilampiño de los cursantes de Apolo", que, preñada de genialidades la mente, se cree con derecho a repetir los versos del clásico Valbuena:

A alcanzar con mi pluma a donde quiero, fuese Homero el segundo, yo el primero.

¿Y qué manera de hacerse artistas, escritores y poetas! Leyendo a Walt Whitman, en él se explica uno la naturaleza espontánea, bravía, y la democracia cruda, hechas en sus versos, por modo excepcional, hombre armonioso y representativo: tal la fuerza creadora 
de su numen. Con nuestros vates de agua y lana es otra cosa: aunque se creen y logran hacerse llamar ungidos poetas, estos Homeros de mentirijillas, enclenques, canijos y escuchimizados, no alcanzan a enredar un estribillo en los roncos bordones de sus laúdes. ¿ Por qué? Porque los verdaderos artistas no se hacen, entendiendo por tales esos seres privilegiados que "piensan cosas admirables, dignas de hablarse a la posteridad", y que saben escribirlas con destreza y música inefables. Sin cultura, sin elevación mental, sin la introspección, sin la sugestión, sin la fuerza emotiva y adivinadora, sin ese gusto tan difícil de obtener fuera del contacto con el arte, con los libros, con los artistas y sobre todo con la naturaleza, sir estilo, en fin, podrán llenar el mundo copleros rasos, buhoneros ambulantes del Pindo, pero no poetas ni escritores auténticos y nobles.

Asienta Revilla en su estudio sobre Fernández Grilo, que poeta de primer orden es aquel que sabe encerrar en el molde hermoso de una versificación perfecta un pensamiento grande, original y profundo, o un sentimiento intenso y vivo que llegue al alma del lector $\mathrm{y}$ engendre aquel placer singular que de lo bello nace y que a un tiempo mismo afecte a la inteligencia y al corazón, a la fantasía y a' los sentidos.

Gómez Restrepo, como poeta, cumple las condiciones de que habla Revilla, para probar lo cual basta estudiar su obra que, por fortuna, ya vió la luz por disposición de la Academia Colombiana y gracias a la diligente laboriosidad del benemérito padre José J. Ortega, ilustre salesiano, a quien deben las patrias letras el más completo estudio de su historia. Con José Joaquín Casas, Arciniegas, Diego Uribe, Enrique W. Fernández... forma la gloriosa agrupación de poetas que sucedió a la ilustre pléyade integrada por Gutiérrez González, los Caros, Pombo, Fallon, Arboleda y Ortiz. Gómez Restrepo es de aquellos que "no entraron en la corriente innovadora (de Silva, de Valencia) y que escribieron de acuerdo con su genialidad". Sabedor de que toda escuela es una limitación, no quiso ponerle trabas a su musa y, heredero de las virtudes y del gusto clásico de sus grandes maestros españoles y colombianos, echó a volar sus cantos, que "fueron aplaudidos de los conocedores, por la armonía de la versificación, la nitidez del lenguaje y lo profundo del sentimiento", según el sabio concepto de don Rufino José Cuervo. 
Si la critica habla su lenguaje propio por boca de Gómez Restrepo, la poesía habla el suyo por esa misma boca. "Amor supremo" es joya de nuestro parnaso, y en su género no tiene semejante; $y$ los otros cantos de su primera época, como "Viaje a Grecia", "Leyendo a Homero", "Adiós", "A una sevillana", además de su impecable corte clásico, revelan un alma de verdadero artista' que por las ideas, por el sentimiento, por la profundidad y por otras excelsas condiciones no le va en zaga a ninguno de cuantos en España y en América han rimado sus propias emociones con perfección insuperable, cumpliendo así el conocido precepto de Boileau:

Soyez vous à vous même un sevère critique.

Algunos de sus versos recuerdan la música que despiertan los de "El lago" de Lamartine:

\author{
$Y$ es mi barquilla leve \\ la concha azul de la deidad de Gnido \\ que esbeltos cisnes de color de nieve \\ arrastran sobre el piélago dormido...
}

"A una sevillana" es otro dechado de armonia, de gracia y de primor descriptivo, que con las tituladas "Recuerdos de Sevilla", "Castellana" y algunas otras emparientan con los mejores versos de líricos como Pombo y el propio Darío.

EI volumen de versos de Gómez Restrepo contiene seis partes: Ecos perdidos, Sonetos, Cantos de Giacomo Leopardi, Poesías varias, En la región del ensueño y Relicario. Creemos que lo mejor de su obra original está en Eicos perdidos, en sus noventa sonetos y en Relicario, cuyos cantos son quejas del más acerbo dolor por la muerte de la mujer amada; intensos, sinceros, delicadas urnas de emoción, como los que consagraron Diego Uribe y Federico Balart a sus esposas muertas, en libros que no habrán de morir porque son la voz del corazón. La versión de los treinta y cinco cantos de Leopardi ponen al autor a la altura de nuestros grandes traductores: Caro, Pombo, Valencia, Arciniegas y Castillo; y con este admirable aporte a la literatura castellana ha hecho lo que ninguno de los literatos de habla española, dándonos a conocer, en versos magníficos, el alma, los sentimientos, dolores, desencantos y desolaciones 
de uno de los más grandes poetas universales. Los sonetos son magistrales y pueden rivalizar con los mejores de los poetas españoles y americanos; armonía, arte, idea, grandiosidad, pasión, dulzura, esas sus principales cualidades. Lástima que en algunos se mezclen asonancias de las rimas de los tercetos con los cuartetos; y aun cuando esta irregularidad no es pecado grave contra el arte, habría sido mejor que la pulcritud de la forma, en este caso, no hubiera dejado nada que desear, como sucede con los restantes sonetos de la serie, de la cual copiamos, para regocijo de los maestros del arte, el titalado "Ulises", que con "Héctor" de José Eusebio Caro y "Homero" de Valencia, forma el trío de sonetos de este género que ennoblecen las páginas del parnaso colombiano:

Víctima del rigor de la fortuna

el padre Ulises al azar navega :

esquivo el sueño su dulzor le niega

y e! anhelo de patria lo importuna.

Isla genial, de las sirenas cuna, descubre el héroe en su derrota ciega, y oye muelle canción, a usanza griega, en que el hechizo a la pasión se aduna.

Atado al mástil el astuto aquivo, hace que el timonel vire en redondo para escapar al pérfido atractivo:

y él, con anhelo delirante y hondo, ve deslizarse sobre el mar lascivo de las sirenas el cabello blondo.

Podríamos transcribir por el estilo muchas joyas de tantas como en el libro aparecen, para que los lectores vean que no exageramos al afirmar que el critico va a la par del poeta y del escritor en Gómez Restrepo, por tan alta manera, que dudamos haya muy pocos, si alguno, que se le puedan igualar en la posesión de estos tres títulos, que hacen de él, a cabalidad, uno de los más ilustres letrados de la América hispana y uno de los pocos representantes de la cultura y de la escuela clásica que aún nos queda en esta nuestra bien o mal llamada Atenas suramericana.

$\mathrm{Si}$ a todas estas prendas literarias juntamos las personales, sobre todo la bondad y la modestia, que hermosean y ennoblecen 
la inmaculada vida de don Antonio - como lo llaman sus amigos más intimos-, tendremos fundido en una sola pieza el varón ejemplar, uno de tantos que estos pueblos de América necesitan para poder llamarse herederos de las glorias literaria's de que se ufanan otros centros más adelantados. Por eso pueden aplicársele al hombre bueno, al grande artista, al docto crítico, al ilustre escritor Gómez Restrepo, las palabras stgestivas y luminosas de un pensador americano, Rodó, también maestro como él en el arte y en las cosas del espíritu: "Decir las cosas bien, tener en la pluma el dón exquisito de la gracia y en el pensamiento el de la inmaculada linfa de luz donde se bañan las ideas para aparecer hermosas, ¿no es una forma de ser bueno? La caridad y el amor ¿ no pueden demostrarse también concediendo a las almas el beneficio de una hora de abandono en la paz de la palabra bella, la sonrisa de una frase armoniosa, el beso en la frente de un pensamiento cincelado, el roce tibio y suave de una imagen que toca con su ala de seda nuestro espíritu? Hablad con ritmo, cuidad de poner la unción de la imagen sobre la idea, respetad la gracia de la forma, ; oh pensadores, sabios, sacerdotes!, y creed que aquellos que os digan que la verdad debe presentarse en apariencias adustas y severas, son amigos traidores de la verdad".

\section{El historiador literario}

En los últimos años ha seguido siendo el mismo incansable escritor, el secretario perpetuo de la Academia Colombiana, a la cual ha vinculado su nombre definitivamente; y a pesar de sus penas morales y físicas, que sobrelleva con cristiana resignación y grande entereza, está escribiendo su obra fundamental, la Historia de la literatura colombiana, de la cual han visto la luz los dos primeros volúmenes, 1 verdadero monumento literario que será uno de los más altos exponentes de la cultura patria.

El primer volumen comprende siete capitulos y un apéndice, fuera de la introducción, magnífico estudio de conjunto, digno de la pluma que lo escribió. Alli se trata de don Gonzalo Jiménez de Quesada; de Juan de Castellanos; de un certamen poético en la colonia; del doctor Hernando Rodríguez Camargo y de sus poesías líricas; de don Francisco Alvarez de Velasco y Zorrilla y de varias 
de sus poesías; de don Francisco Antonio Vélez Ladrón de Guevara y de algunos de sus versos; de dos poetisas desconocidas; de una traducción de Virgilio; de una tragedia de Racine, y de un precursor del teatro colombiano.

De más está decir que el desarrollo de estas materias, de suyo delicadas y complicadas - obra de erudito y de artista-, está hecho de mano maestra, pues como nadie, Gómez Restrepo conoce nuestra literatura en todos sus pormenores, dado que desde muy atrás viene consagrándole, con la diligencia de incansable apóstol, los nobles esfuerzos de su pluma y de su mente. La prensa del país elogió en cálidas frases, acaso menos de lo que debiera, la aparición de esta obra que honra verdaderamente a la patria ; y la prensa extranjera está diciendo palabras de admiración y de justicia en obsequio de este nuevo libro colombiano, como lo indica el magnífico estudio que el eximio escritor mexicano Alfonso Méndez Plancarte publicó en la revista Abside de enero de 1939, y que termina con estas nobles palabras: "Bella y utilísima obra, por tanto, esta que para gloria de Castilla, de Colombia y de toda América va construyendo tan noble señor de las letras neogranadinas, dejándonos con hambre de ver muy pronto la prosecución y el coronamiento de su alta empresa".

El segundo volumen comprende veinticinco capitulos y un apéndice; en ellos se estudia lo relativo a la predicación, al culteranismo criollo y a la literatura ascética y mistica, y lo referente a la vida y la obra de la madre Francisca Josefa del Castillo y Guevara, del doctor Juan Bautista de Toro, de la madre María Petronila Cuéllar, de Juan Rodríguez Freile, de Alonso Garzón de Tahuste y Lucas Fernández de Piedrahita, del padre Alonso de Zamora, del padre Manuel Rodríguez, del padre Francisco de Figueroa, de fray Andrés de San Nicolás, de don José de Oviedo y Baños, del padre Pedro Tobar y Buendía, de don Basilio Vicente de Oviedo, de don Manuel Antonio del Campo y Rivas y algunos más. El apéndice contiene, entre otras cosas, el primer canto al Tequendama.

El avance y la importancia que con este volumen va tomando la obra están diciendo que el contenido completo es de tan excelso valor, que sería verdaderamente lamentable para las letras patrias el que ella no llegara a publicarse en toda su extensión. Quiera el cielo prolongar indefinidamente los días del señor Gómez Restrepo 
para que no sólo éste, pero algunos otros partos de su ingenio, sea la cosecha que en sus años maduros deje a la patria y a las letras americanas.

Digno de loa, por lo justiciero y reivindicador, es el capítulo que el autor consagra a don Manuel Antonio del Campo y Rivas. Particularmente el Valle del Cauca, y especialísimamente la ciudad de Cartago - cuna del talento, según Alcedo- que vió nacer y crecer en su seno a este ingenio peregrino y andariego que por doquicra dejó rastros luminosos, les quedarán agradecidos tanto al autor de la Literatura como al doctor Raimundo Rivas por su generoso*empeño de reclamar para Colombia la gloria de haber producido personaje tan prestante en derecho y en letras, y que por sus efectivos servicios a la corona de España mereció la distinción de que el rey Carlos IV lo nombrara oidor y alcalde de corte de la real audiencia de Guatemala, de donde pasó con igual cargo a Guadalajara y luego a la ciudad de México, en donde falleció. De él acaba diciendo el señor Gómez Restrepo: "Ese oidor ejemplar, ese fiel servidor de la corona, encabeza uno de sus capítulos con las siguientes frases, que parecen tomadas de una de las diatribas que con tanta frecuencia se escriben contra la conquista. Es uno de esos brotes de independencia que ya hemos anotado en escritores coloniales nacidos en el Nuevo Reino: ' $L_{4}$ a historia de los conquistadores por lo común, es la de los destructores del género humano. Cuando la ansia de dominar se junta a la crueldad de esos pretendidos héroes, se horroriza la humanidad'."

Por lo demás, es la hora de advertir que nadie hasta hoy en Colombia ha presentado y estudiado cumplidamente a cada uno de los personajes que dan materia a este volumen de la Literatura colombiana, por lo cual no es hiperbólico llamar monumental la obra a que nos estamos refiriendo, y a su autor uno de los más altos exponentes de las letras patrias y de la cultura universal.

Escritores de mayor prestancia intelectual (ya lo dijimos) pondrán en su punto algún día los relevantes méritos y extraordinarias virtudes de este verdadero profesor de energía que es Antonio Gómez Restrepo, incomparable mantenedor de las letras colombianas. Ojalá este ligero estudio, inspirado en la justicia y la admiración, sea acicate para que no falte en los anales de nuestra cultura 
la obra cumplida que consagre el nombre de este insigne compatriota.

Manuel Antonio Bonilia,

Ibagué, Colombia.

NOTA

1 A. G. R. Historia de la literatura colombiana. Publicaciones de la Biblioteca Nacional de Colombia, Imprenta Nacional, núms. 1 y 2. Vol. I, Bogotá, 1938, 331 pp.; Vol. II, Bogotá, 1940, 380 pp. 